UDC: (640.4+004.738.12):811 https://doi.org/10.22190/JTESAP1801083Y

\title{
MOVE AND WRITING STRATEGY ANALYSIS OF INTERNATIONAL HOTEL HOMEPAGES
}

\author{
Chalita Yaemwannang ${ }^{1}$, Issra Pramoolsook ${ }^{2}$ \\ Suranaree University of Technology, Thailand \\ 1E-Mail: lita ya@hotmail.com, ${ }^{2}$ E-Mail: issra@sut.ac.th
}

\begin{abstract}
Thailand is one of the most visited tourist destinations in the world. Hotel is one of the factors in decision making process when tourists select their travel destinations. Thailand offers a wide range of accommodation for every type of budget. Therefore, the hospitality industry in Thailand is highly competitive. It is important for hoteliers to advertise their places effectively in order to increase the hotel brand awareness and the number of hotel bookings. Particularly, the target customers of hotel in general are not only limited to domestic travelers but also international. Advertising through the hotel official websites helps reach the target audience from all over the world, so organizing the content on the website plays an important role in making the advertising effective. This paper therefore aims to analyze the moves and their structure in the content area of popular international hotel homepages and also the writing strategies used in each move. Twenty four hotel homepages from eight different countries were selected for the analysis. The generic structure of advertisement proposed by van der Vliet \& Redeker (2014) was used as the analysis framework. The main results show that there are differences between moves found in the present study and van der Vliet \& Redeker (2014)'s work. Additionally, there is a variety of writing strategies found in each move that help deliver its common communicative purposes.
\end{abstract}

Key words: hotel homepages, promotional discourse, move analysis, English for Specific Purposes ESP, writing strategies.

\section{INTRODUCTION}

There are many ways to promote products and services in tourism and hospitality industry, for example, books, brochures, billboards, and the Internet. These channels aim to provide promotional materials and activities in order to inform, persuade, and stimulate different target audiences. However, the most cost-effective and the fastest way to advertise products and services and to promote business globally is through the use of the Internet. The rise of the Internet has changed the way people communicate and do business. For tourism industry, the Internet allows tourism entrepreneurs to promote their products globally at a much lower cost than traditional promotional tools. A website is important for any business because it not only allows customers to research product information before making a purchase, but also helps establish credibility and impression of a company. It is acknowledged that the company's homepage is the most important page of the whole website (McGovern \& Norton, 2001; Kyrnin, 2007; Parker, 2012; 
Myers, 2012; Landa, 2013), so this page should be both informative and attractive in order to seize customers' attention.

It is important to emphasize that the offering in tourism and hospitality industry is both tangible and intangible. That is, this industry offers customers the products that can be seen, such as a hotel room, and also the aspect of tourism that cannot be seen or touched by customers, such as services a hotel gives. Therefore, it is essential for tourism and leisure marketing to be able to promote the intangible values and experiences and help create the perceived value of the products. Besides the beautiful pictures that catch the eyes of the target customers, the content posted on hotel homepages needs to be able to deliver those features in an attractive, persuasive, and informative way in order to compete in such a competitive business environment successfully. Therefore, it is worth exploring the information and organization of the textual elements presented in the content area and the writing strategies used in international hotel homepages. This study aims to investigate hotel homepages according to the research objectives below:

1. To analyze the moves and their structure of the textual elements in the content area of the homepages of popular international hotel websites,

2. To examine the writing strategies used in each move found from research.

Objective 1

The main research questions are thus the following:

1. What are the moves and their structure in the content area of the homepages of popular international hotel websites?

2. What are the writing strategies used in each move found from Research Question 1?

\section{LITERATURE REVIEW}

\subsection{Promotional genre in tourism}

Promotional discourse aims to inform and promote ideas, products, or services to a particular group of people. Advertisement is a form of promotional discourse for marketing communication that can help deliver promotional messages to the target customers. In the context of tourism industry, its advertising is different from other industries in terms of its products in the sense that most of the products and services available in tourism industry are both tangible, such as souvenirs and intangible, such as a package holiday. Customers buy the intangible products on the basis of symbolic expectations which can be demonstrated through words, pictures, sounds and other media. Therefore, leisure and tourism experiences are being established in customers' imagination through media and advertising. It is stated that tourism marketing is all about selling of dreams, and tourism by itself is an illusion. Particularly, tourism and leisure operators use a lot of images in their advertising in order to help the viewers construct an image of certain destinations, places, products and services in their mind (Morgan \& Pritchard, 2000). Therefore, tourist brochures and advertising consist of several images and text altogether.

One of the most effective ways for businesses to advertise is through online advertising. The Internet is one of the primary tools used for searching for information and it allows consumers and businesses to communicate to one another easily. Additionally, consumers nowadays use the Internet to seek for information, and rely on those pieces of information to make decision and reservations (Sabaruddin et al., 2015). Especially, consumers nowadays 
can go through countless travel websites to research travel information, images and online reviews. With a wide-reaching access to the travel information that can be done online, there is a rapid growth of travel websites to facilitate consumers for online searching. Specifically, the basic goals of a website are varied. For example, some companies may use websites to provide information, to sell products or services, to build company's reputation, or to serve as an online store (Minnick, 2016). Even so, Gregory et al. (2010 cited in Sabaruddin et al., 2015) assert that information is the primary reason why individuals visit a website. Besides, the information on the web is considered as the most fundamental element of a website.

\subsection{Generic structures in promotional materials}

There are several studies that have analyzed moves and their structure of advertisement, for example, Bhatia (2004; 2005), Labrador et al. (2014), van der Vliet \& Redeker (2014), and Luo \& Huang (2015) However, these studies have different focuses. For example, Bhatia (2004; 2005) investigated hotel printed advertisement, van der Vliet \& Redeker (2014) investigated magazine advertisement, whereas Labrador et al. (2014) and Luo \& Huang (2015) investigated tourist brochures.

The current study used van der Vliet \& Redeker (2014)'s generic structure as the analysis framework. This structure was developed from the well-known generic structure of hotel printed advertisement proposed by Bhatia (2005). So, it should have a solid foundation for the analysis. From their study, there are nine moves that play important functional elements of such advertisement. Table 1 compares the original generic move structure from Bhatia (2005) and that from van der Vliet \& Redeker (2014) in order to highlight some differences between the two.

Table 1 Bhatia (2005) and van der Vliet \& Redeker (2014)'s generic structures of advertisement

\begin{tabular}{|c|c|}
\hline $\begin{array}{l}\text { Bhatia (2005)'s generic structure of } \\
\text { printed advertisement }\end{array}$ & $\begin{array}{l}\text { van der Vliet \& Redeker (2014)'s generic } \\
\text { structure of advertisement }\end{array}$ \\
\hline Move 1: Headlines (to attract attention) & Move 1: Get attention \\
\hline Move 2: Targeting the market & Move 2: Establish a niche \\
\hline $\begin{array}{l}\text { Move 3: Justifying the product or service } \\
\text { by establishing a niche }\end{array}$ & Move 3: Detail the product/service \\
\hline Move 4: Detailing the product or service & Move 4: Establish credentials of the company \\
\hline Move 5: Establishing credentials & Move 5: Endorsement or testimonials \\
\hline Move 6: Endorsement or testimonials & Move 6: Offer incentives \\
\hline Move 7: Offering incentives & Move 7: Use pressure tactics \\
\hline Move 8: Using pressure tactics & Move 8: Solicit response \\
\hline Move 9: Soliciting response & Move 9: Reference to external materials \\
\hline nd $\log$ & \\
\hline
\end{tabular}

From their results, van der Vliet \& Redeker (2014) excluded two moves from Bhatia's (2005) which are Move 2: Targeting the market and Move 10: Signature line and logo. However, they found a new move that does not exist in Bhatia (2005), which is Move 9: Reference to external material. The communicative purpose of each move is adapted from Bhatia (2005) and is explained, as follows; 
Move 1: Get attention. This move is used to attract customers' attention.

Move 2: Establish a niche. This move helps justify the products or services by establishing a niche.

Move 3: Detail the product/service. This move aims to describe and identify product or service.

Move 4: Establish credentials of the company. This move aims to build trust and credentials which can be done by indicating celebrity endorsement and stating positive and long established service records.

Move 5: Endorsement or testimonials. Similar to Move 4, this move aims to build trust and credentials which can be done by indicating endorsement given by authorized organization and pinpointing testimonials.

Move 6: Offer incentives. The communicative purpose of this move is to offer special offers and/or discount to customers.

Move 7: Use pressure tactics. Similar to Move 6, the communicative purpose of this move is to offer special offers and/or discount to customers. However, the difference is that this move offers savings only if customers purchase products or services within a specified deadline.

Move 8: Solicit response. This move aims at encouraging further individual communication by providing information such as address, email address, and contact number.

Move 9: Reference to external materials. The communicative purpose of this move is to provide further relevant materials to customers.

\subsection{Writing strategies used in promotional materials}

Aside from moves and their structure, the current study is also interested in examining writing strategies used in each of the moves identified, which is highly influenced by the study on writing strategies used in tourist brochures from Luo \& Huang (2015). According to their findings, there are 8 moves in the generic structure of the tourist brochures included as their data and their corresponding writing strategies found in each move are presented, as follows;

Move 1: Attract tourists' attention. Two strategies are used to attract tourists' attention. Firstly, it can be done by stating the name of tourist destination, for example, BAY CITY GUIDE-EXPLORE SAN FRANCISCO. Secondly, it can be done by highlighting specialties, for example, TOUR IN SAN FRANCISCO: YOSEMITE TRAIN TOURS, PREMIUM WINE TOURS.

Move 2: Targeting the market. In their study, targeting the market can be done by two strategies; by defining keywords (e.g. CARMEL: DOG-FRIENDLY TOUR \& ECOFRIENDLY TOUR), and by defining the theme of tours (e.g. Content of CARMEL: The great outdoors, wining and dining, be enlightened by arts, and history buff). These two strategies are used to build up potential customers' interest and attract them to find further information.

Move 3: Establish credentials. These elements display elaborate descriptions to indicate destination's uniqueness, and positive feedback from authorities or visitors. There are two strategies used to establish credentials; by indicating the value of the tourist destination (e.g. "The most significant mention received was that of Monterey County being designed as one of the top 10 wine destinations in the world, and Carmel is the only destination in California to make the list!"), and by giving endorsement (e.g. "Carmel was rated \#3 in the list of the world's best cities for romance"). 
Move 4: Highlighting specialties. This move is to persuade tourists to select the travel destination by pinpointing the outstanding projects, for example, Muir Woods \& Sausalito: 1000 Years Old-Tallest Trees in the World.

Move 5: Detailing the tourist destination. There are two strategies found in this move, which are by introducing the tourist destination (e.g. Glen Canyon: (followed by the introduction part of the destination)), and by recommending itineraries (e.g. Yellowstone; Tour 1: Old faithful to Mammoth hot spring, Tour 2: Tower-Roosevelt and Canyon Village). Normally, the details of tourist destination regarding its history, geology, and so on are provided in this move.

Move 6: Offering incentives. There are two strategies used; by providing preferential policy (e.g. Become a USS Midway Member!: Get discounts and bring friends and family back all year long for FREE), and by providing additional services (e.g. FREE Hotel Pick-Up \& Drop off).

Move 7: Providing service information. It is the original function of tourist brochures to provide contact information or service information. There are several details provided in this move, for example, location, open hours, fee, and accessibility.

Move 8: Solicit responses. As for tourist brochures, it is obligatory to offer tools for soliciting responses such as addresses, telephone numbers, official website, and social network accounts. This information is used to offer assistance or to get feedback from customers.

It can be seen that there is a variety of writing strategies that can be used in each move to deliver the same communicative purpose. This present study, therefore, also aims to analyze writing strategies used in the textual elements of hotel homepages with the hope to identify how each move is composed to achieve its communicative purposes.

\section{METHODOLOGY}

The current study adopted van der Vliet \& Redeker (2014)'s generic structure of advertisement as the analysis framework to investigate moves and their structure of hotel homepage because of three reasons. Firstly, this generic structure was proposed from an analysis of commercial advertisements from magazines, and was developed from the well-known generic structure of printed advertisement by Bhatia (2005). Therefore, this generic structure should have a solid foundation for the analysis. Secondly, there are certain similarities and differences between these two generic structures which are already clearly explained in the literature review part. Some moves from Bhatia (2005) are excluded from van der Vliet \& Redeker (2014)'s work, and one new move is suggested. Finally, the van der Vliet \& Redeker (2014)'s generic structure is more up-todate, and therefore, more applicable for this research.

The hotel homepages included into this study were selected based on the combination of three sampling methods; purposive, quota, and stratified. Specifically, the countries participating in this corpus were purposively selected based on their rankings on the 'top ten most visited countries around the world' provided by The World Tourism Organization (2015). Then, quota sampling method was applied. The ranking of the top three most visited cities in each country provided by the website TripAdvisor was utilized in this process. According to this ranking, China, Macau and Hong Kong can be merged into the same location since Hong Kong and Macau were listed in the top most visited cities in China. So, they should not be treated as separate countries from China. All in all, there 
are 8 destinations in total to be analyzed in this study. Finally, for stratified random sampling method, since the present study aims to analyze hotel homepages from 8 countries, sometimes there are multiple languages used in these official websites. However, this present research would like to focus solely on English language websites, so if any of the websites listed in the top 3 ranking does not provide the English language version, those sites were excluded. Instead, the websites which are placed in the latter ranking were chosen. The screenshots of the 24 hotel homepages were made on 1 October 2016 and they were coded as HUS01-02, HSP01-03, HCH01-13, HFR01-03, HIT01-03, HUK01-03, HGE01-03, and HTH01-03, respectively. The names of 24 hotels selected to be in the current corpus are listed in Table 2.

Table 2 The present research's hotel corpus

\begin{tabular}{|c|c|c|}
\hline Destination & Hotel name & Coding \\
\hline \multicolumn{3}{|l|}{ United States } \\
\hline - New York city & - Casablanca Hotel Times Square & HUS01 \\
\hline - Chicago & - The Langham Chicago & HUSO2 \\
\hline - Charleston & - Wentworth Mansion & HUS03 \\
\hline \multicolumn{3}{|l|}{ Spain } \\
\hline - Barcelona & - The Serras Hotel Barcelona & HSP01 \\
\hline - La Olivia & - Avanti Hotel Boutique Fuerteventura & HSP02 \\
\hline - Seville & - Corral del Rey & HSP03 \\
\hline \multicolumn{3}{|l|}{ China } \\
\hline - Hongkong & - The Ritz-Carlton Hong Kong & $\mathrm{HCH} 01$ \\
\hline - Beijing & - Beijing Double Happiness Courtyard Hotel & $\mathrm{HCH} 02$ \\
\hline - Shanghai & - Mandarin Oriental Pudong & $\mathrm{HCH} 03$ \\
\hline \multicolumn{3}{|l|}{ France } \\
\hline - Paris & - Tamise Hotel & HFR01 \\
\hline - Nice & - Hyatt Regency Nice Palais de la & HFR02 \\
\hline - Marseille & Mediterranee & HFR03 \\
\hline & - Intercontinental Marseille-Hotel Dieu & \\
\hline \multicolumn{3}{|c|}{ 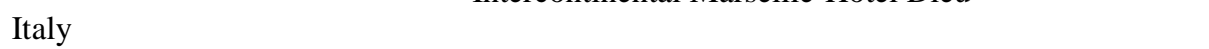 } \\
\hline - Rome & - Deko Rome & HIT01 \\
\hline - Florence & - Grand Amore Hotel \& Spa & HIT02 \\
\hline - Venice & - Hotel Al Ponte Antico & HIT03 \\
\hline \multicolumn{3}{|l|}{ United Kingdom } \\
\hline - London & - Hotel 41 & HUK01 \\
\hline - Edinburgh & - The Raeburn & HUK02 \\
\hline - Llandudno & - Elm Tree Hotel & HUK03 \\
\hline \multicolumn{3}{|l|}{ Germany } \\
\hline - Berlin & - Das Stue & HGE01 \\
\hline - Munich & - The Charles Hotel & HGE02 \\
\hline - Hamburg & - Fairmont Hotel Vier Jahreszeiten & HGE03 \\
\hline \multicolumn{3}{|l|}{ Thailand } \\
\hline - Bangkok & - Mandarin Oriental Bangkok & HTH01 \\
\hline - Chiangmai & - The Dhara Dhevi Chiangmai & HTH02 \\
\hline - Pattaya & - Royal Wing Suites \& Spa & HTH03 \\
\hline
\end{tabular}

The frameworks used to segment homepages in the present corpus were adapted from West (2013) and Minnick (2016) which categorize homepage elements into 3 main areas; 
namely, header, content, and footer area. Figure 1 illustrates how a hotel homepage is segmented into three main areas following the two chosen frameworks. To illustrate, a header, logo, and navigation bar were categorized into the header area. Banners, textual contents, pictures, and articles were categorized into the content area, and the section that contains information placed at the bottom of homepage was categorized into the footer area. The textual elements used in the move analysis were selected from the content area of the hotel homepages.

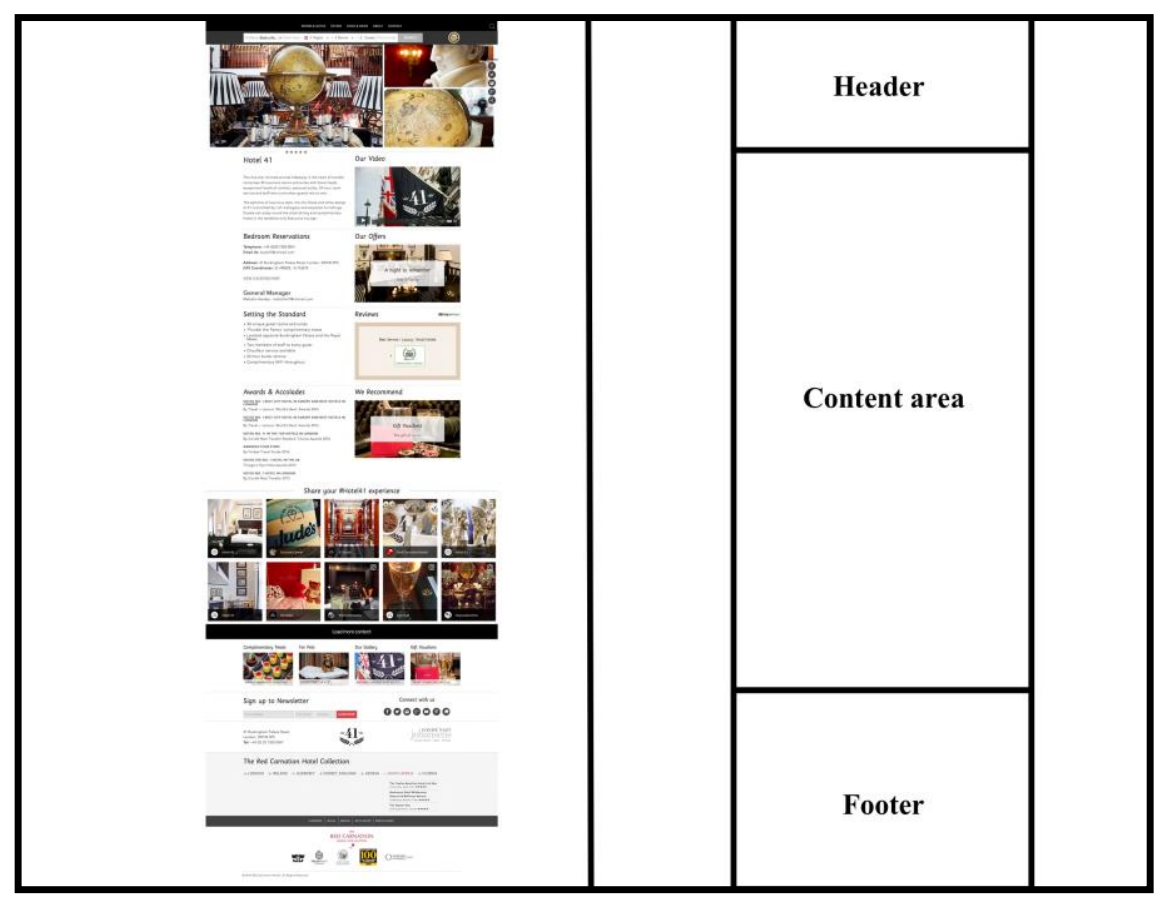

Fig. 1 The desktop homepage layout of HUK01

To increase reliability of the analysis, inter-coder reliability was conducted to analyze $30 \%$ of the hotel homepages. Two experienced professors in English Language Teaching were invited as inter-coders. One holds a $\mathrm{PhD}$ in Linguistics and the other received an EdD in Applied Linguistics. This research relied on the percentage of agreement. Each coder coded the similar case separately, and then the final coding was compared among the two invited coders and the researchers of this investigation. The final result showed that the percentage of agreement is $96 \%$ which means sufficient and acceptable agreement.

\section{RESULTS AND DISCUSSION}

According to van der Vliet \& Redeker (2014), there are 9 common moves found in online advertisements. From the current analysis of the present study, all 9 moves from van der Vliet \& Redeker (2014) were found in the hotel corpus. Besides, there is one extra move that does not exist in van der Vliet \& Redeker (2014)'s framework which is 
'Provide detail of tourist attraction*'. The detail of each move will be elaborated in the later sections.

Importantly, it was found that some pieces of text in the content area can serve more than 1 communicative purpose, therefore they can function as multiple moves in this study. The researchers believe that one text does not necessarily function as 1 specific move only. For example, hotels use headlines and images to attract attentions from customers (Move 1). However, textual elements used to grab customers' attraction can also convey other messages. More details will be shared in the following section. Table 3 below provides a summary of the moves found in the corpus of the hotel homepages, including their frequency and examples. All the moves found in this study are arranged in Table 3 according to their frequency.

Table 3 A summary of moves and examples found in the hotel corpus

\begin{tabular}{|c|c|c|c|}
\hline & Moves & Examples & $\begin{array}{l}\text { Frequency } \\
(\mathbf{N}=\mathbf{2 4})\end{array}$ \\
\hline 1 & Get attention & Welcome to Fairmont Hotel Vier Jahreszeiten (HGE03) & $24(100 \%)$ \\
\hline 2 & $\begin{array}{l}\text { Detail the } \\
\text { product/service }\end{array}$ & $\begin{array}{l}\text { Hyatt Regency Nice Palais de la Méditerranée features } \\
\text { luxurious and spacious accommodation including } 187 \\
\text { guest rooms and } 9 \text { elegantly furnished suites. (HFR02) }\end{array}$ & $23(95.8 \%)$ \\
\hline 3 & $\begin{array}{l}\text { Establish } \\
\text { credentials of the } \\
\text { hotel }\end{array}$ & $\begin{array}{l}\text { Mandarin Oriental Pudong, Shanghai is five-star } \\
\text { luxury hotel spectacularly located on the banks of the } \\
\text { Huangpu River. (HCH02) }\end{array}$ & $16(66.6 \%)$ \\
\hline 4 & Offer incentives & $\begin{array}{l}\text { Book with Rocco Forte Hotels to receive: } \\
\text { - Complimentary High-speed Wi-fi } \\
\text { - A complimentary seasonal food and beverage offer } \\
\text { - Early exclusive access to promotions } \\
\text { - Early arrival and late check out (Subject to availability) } \\
\text { - Best rate guaranteed (HGE02) }\end{array}$ & $12(50 \%)$ \\
\hline 5 & $\begin{array}{l}\text { Endorsement or } \\
\text { testimonials }\end{array}$ & $\begin{array}{l}\text { \#2 Best Luxury Hotel in the US - } 2017 \text { TripAdvisor } \\
\text { Travelers' Choice Award (HUS03) }\end{array}$ & $11(45.8 \%)$ \\
\hline 6 & Solicit response & $\begin{array}{l}\text { - Corral Del Ray, } 12 \text { Seville, Andalucia, 41004, Spain } \\
\text { - +34954227116 } \\
\text { - info@corraldelray.com (HSP03) }\end{array}$ & $11(45.8 \%)$ \\
\hline 7 & $\begin{array}{l}\text { Reference to } \\
\text { external material }\end{array}$ & Follow us on (insert social media logos) (HGE02) & $7(29.1 \%)$ \\
\hline 8 & Establish a niche & $\begin{array}{l}\text { The Raeburn was built in } 1832 \text { as an elegant Georgian } \\
\text { family home and has now been transformed into an } \\
\text { exquisite boutique hotel, boasting ten bedrooms, bar, } \\
\text { restaurant, library, private dining and conference } \\
\text { room and outside terraced area, the only one of its } \\
\text { kind in the area. (HUK02) }\end{array}$ & $6(25 \%)$ \\
\hline 9 & $\begin{array}{l}\text { Provide detail of } \\
\text { tourist } \\
\text { attraction* }\end{array}$ & $\begin{array}{l}\text { Be prepared for the dizzyingly fast pace of Shanghai } \\
\text { and be wowed by its futuristic architecture. But take } \\
\text { time to discover its quiet spots, too. }(\mathrm{HCH} 03)\end{array}$ & $6(25 \%)$ \\
\hline 10 & $\begin{array}{l}\text { Use pressure } \\
\text { tactics }\end{array}$ & $\begin{array}{l}\text { Advance spring offer booking } 1 \text { st - 30th Marcg: save } \\
15 \% \text { off the Best Available Rates. Offer applicable to } \\
\text { all room categories. (HSP03) }\end{array}$ & $2(8.3 \%)$ \\
\hline
\end{tabular}

Note: * means new extra move that does not exist in van der Vliet \& Redeker (2014). 
None of the 24 hotel homepages consists of nine moves altogether. From the findings, 'Move 1: Get attention' is the only move found in all the hotel homepages (100\%), followed by 'Move 2: Detail the product/service' which achieves $95.8 \%$ occurrence. Next, 'Move 3: Establish credentials of the company' occurs less frequently at $66.66 \%$ of the corpus, followed by 'Move 4: Offer incentive' (50\%). According to these frequencies, it can be concluded that only Move 1 is considered as an obligatory move. Move 2, and Move 3 are conventional moves, and Move 4 to Move 10 are optional moves, following the criteria proposed by Rasmeenin (2006). Below are the details of the nine moves found in this present study.

Move 1: Get attention. All hotel homepages have this move. The communicative purpose of this move is to grab attention and give readers a preview of what to expect on the content. There are two writing strategies that can be used to attract the readers' attention, which are headlines and visual images. Headlines are usually big, bold, and outstanding. Font and font size play an important role to attract a crowd and make an impact. It is important for businesses to create standout headlines, so they can draw attention to the parts of text. However, headlines are not necessarily written in a full sentence form, but can be nouns and noun phrases, for example, Stay longer in Hong Kong to enjoy more (HCH01), and Pick your perk (HUS01). The second strategy is to use visual images to capture the readers' interest. Specifically, images are organized closely to the headline to create more impact and entice the readers to read the content posted.

Move 2: Detail the product/service. Twenty-three hotel homepages employ this move. The communicative purpose of this move is to describe the detail of product or service. In the case of hotels, there is a variety of products/services that they offer to their customers, such as rooms, meeting venues, in-house restaurants, spas, and hotel locations. Besides, hotels also like to make a promise to customers that they will experience a remarkable service when they stay in their hotels. In other words, there are 2 writing strategies used; describing product/service details and making a promise. It is also found that all the hotels provide images of their places on their homepages.

- With 324 elegant rooms, 44 luxurious suites, innovative restaurants and a worldclass spa, Mandarin Oriental, Bangkok offers a luxurious five-star experience (HTH01): Describing product/service detail

- The intimate setting of our hotel with its elegant rooms allow us to offer you personalized services and a good level of availability to help you throughout your stay in Paris and make your trip a success (HFR01): Making a promise

Move 3: Establish credentials of the hotel. This move aims to create a positive image by building confidence and trust to the hotel. There are 5 writing strategies used; namely, Using celebrity endorsements, Indicating a long establishment of the company, Claiming themselves as a first-mover of a business, Indicating their hotel star rating, and Presenting their staff's achievement. Around two-third of the hotel homepages include this move.

- Welcome to Berlin's first luxury boutique hotel (HGE01): Claiming themselves as a first-mover of a business

- The hotel has been welcoming fashion VIPs, such as Twiggy, models of Madam Grès and great fashion photographer Patrick Demarchelier, for decades (HFR01): Using celebrity endorsements 
Move 4: Offer incentives. The hotels use this move to propose incentives to customers. There are 3 writing strategies used; offering discounts, offering complimentary gifts, and using bribery technique, such as offering customers something extra only if they buy the products or service. $50 \%$ of hotels employ this move.

- For select dates of 4 nights or more, we offer a wonderfully priced package that let's you 'Pick your Perk' and receive one of our most popular and festive welcome amenities for only \$1. Look for this great value offered exclusively on our website! (HUS01): Using bribery technique

- Book your stay 15 days in advance to receive $10 \%$ off your journey to Hong Kong (HCH01): Offering discounts

Move 5: Endorsement and testimonials. This move also aims to establish confidence to the potential customers. There are 2 writing strategies used. Firstly, the hotels indicate testimonials given by customers. Secondly, the hotels indicate endorsement evidences given by people or organizations who recommend the hotel in order to promote their products to the public. The analysis shows that $45.8 \%$ of the hotels mention endorsements and/or testimonials on their homepages. Specifically, the endorsement organization and testimonial sources that can be seen in the present hotel corpus are from Condé Nast traveler, Forbes Travel Guide, and TripAdvisor.

- Das Stue's intimate scale and discreet location, coupled with its generously sized rooms, have instantly put it at the top of the pile - Condé Nast Traveller (HGE01): Indicating testimonials given by customers

- Voted No.11 in the top hotels in London By Condé Nast Traveler Readers' Choice Award 2016 (HUK01): Indicating endorsement evidences given by organizations

Move 6: Solicit response. This move consists of contact details of the hotel. The key writing strategy used provide contact details such as address, telephone number, and email address, which allow customers to contact the hotels directly. In the present corpus, $45.8 \%$ of the hotels have this move.

- Telephone: +44(0) 2073000041

Email Us: book41@rchmail.com

Address: 41 Buckingham Palace Road, London, SW1W OPS

GPS Coordinates: 51.498224, -0.143572

General Manager

Malcolm Hendry-malcolm41@rchmail.com (HUK01)

Move 7: Reference to external material. This move provides other information sources that are available for the readers to interact with. One writing strategy is found which is offering other details for the readers to interact or stay connected, for example, other social media platforms such as Facebook, Twitter, Instagram, or blog. In the current study, only 7 hotels employ this move.

- Explore the area by connecting with us on foursquare, where you can discover others' favorites and share your own. (HCH01) 
- Created for our loyal fans and regular guests. Fans of MO is a place for you to share your favorite Mandarin Oriental experiences. We invite you to discover these moments and submit your own. (HTH01)

Move 8: Establish a niche. In the present corpus, 6 hotels employ this move which helps to indicate the importance or the needs for the product or service, and/or to establish a niche. Two writing strategies are found. Firstly, the analysis has revealed that the detailed description of what hotels offer is complemented with information on the product features that aim at satisfying specific market needs. The hotels can deliberately set out to associate their brands to satisfy specific customers' needs. Secondly, it is found that one hotel establishes a niche by claiming that they are the only hotel who provides certain products/service.

- Hotel adapted for people with reduced mobility: handicap accessible rooms, wheelchair loans and adapted phones (HFR01): Associating their brands to satisfy specific customers' needs

- For Pets, Everyone's a V.I.P (HUK01): Associating their brands to satisfy specific customers' needs

Move 9: Provide detail of tourist attraction*. This particular move is a new move found in the present corpus. Some hotels do not only provide details about their products and services alone, but they also provide further detail about their country, city, or tourist attractions nearby. One writing strategy is found, which is providing details on how amazing the city is. Six hotels or $25 \%$ employ this move in the present corpus.

- An exotic blend of traditional culture, rich history and hip modern style, Thailand's capital is one of Asia'a most cosmopolitan and exciting cities (HTH01)

- Be prepared for the dizzyingly fast pace of Shanghai and be wowed by its futuristic architecture. But take time to discover its quiet spots, too. (HCH03)

Move 10: Use pressure tactics. The hotels use this move to propose incentives to customers. There is 1 writing strategy used. The hotel uses time pressure to influence the customers in decision-making process. $8.3 \%$ of hotels employ this move.

- Book Now to Win Free Airport Pickup! (HCH02)

- Advance spring offer booking 1st - 30th Marcg: save 15\% off the Best Available Rates. Offer applicable to all room categories. (HSP03)

\section{CONCLUSION}

According to the findings, there are 9 moves found in the hotel homepages. However, none of them includes all 9 moves together in their homepages. The common moves used (more than $50 \%$ of all hotel homepages) are Move 1: Get attention (100\%), Move 2: Detail the product/service $(95.8 \%)$, Move 3: Establish credentials of the hotel $(66.66 \%)$, and Move 4: Offer incentives (58.3\%).

Moreover, the current study has identified one new move that does not exist in van der Vliet \& Redeker (2014), which is 'Move 9: Provide detail of tourist attraction'. As the present study analyzed hotel advertising on hotel homepages, while van der Vliet \& 
Redeker (2014) analyzed printed advertising on lifestyle magazines, therefore, the difference could occur due to the different nature of the two types of business.

As for the writing strategies used, varied strategies can be applied when writing the content in each move. For example, there are two writing strategies found that can be used to deliver Move 1: Get attention, which are using headlines and visual images, and there are two writing strategies used in Move 2: Detail the product/service, which are describing product/service in details and making a promise. The findings on the moves and writing strategies used in each move can be used as a guideline and teaching materials to teach students in many fields, such as marketing, and tourism and hospitality fields to write efficient content for hotel homepages. Also, it can be beneficial for hoteliers and web developers who are responsible for writing content on hotel homepages for effective communication of their businesses.

\section{REFERENCES}

Bhatia, Vijay Kumar. Worlds of Written Discourse. London: Continuum, 2004.

Bhatia, Vijay Kumar. "Generic Patterns in Promotional Discourse.” In Persuasion Across Genres: A Linguistic Approach, edited by Halmari, H., \& Virtanen, T., 213-225. Amsterdam: John Benjamins Publishing, 2005.

Kyrnin, Jennifer. About. com Guide to Web Design: Build and Maintain a Dynamic, UserFriendly Web Site Using HTML, CSS and Javascript. Massachusetts: Adams Media, 2007.

Labrador, Belén., et al. "Rhetorical Structure and Persuasive Language in the Subgenre of Online Advertisements." English for Specific Purposes 34 (2014): 38-47.

Landa, Robin. Essential Graphic Design Solutions. Singapore: Thomson Learning, 2013.

Luo, Jing, and Huang, Tingyu. "Genre-Based Analysis of American Tourism Brochure." Open Journal of Social Sciences, 3 (2015): 200-208.

McGovern, Gerry, and Norton, Rob. Content Critical: Gaining Competitive Advantage Through High-Quality Web Content. London: Financial Times Prentice Hall, 2001.

Minnick, Jessica. Web Design with HTML \& CSS3: Complete. Boston: Cengage Learning, 2016.

Morgan, Nigel, and Pritchard, Annette. Advertising in Tourism and Leisure. London: Routledge, 2000.

Myers, Debbie Rose. The Graphic Designer's Guide to Portfolio Design (3rd Eds.). New Jersey: John Wiley \& Sons, 2012.

Parker, Scott. The Web Designer's 101 Most Important Decisions: Professional Secrets for a Winning Website. Ohio: How Books, 2012.

Rasmeenin, Chawalee. "A Structural Move Analysis of MA Thesis Discussion Sections in Applied Linguistics." Unpublished Master thesis. Mahidol University, Thailand, 2006.

Sabaruddin, S. A., Abdullah, N. H., Jamal, S. A., \& Tarmudi, J. "Exploring the Accessibility and Content Quality of the Go2homestay Website," In Theory and Practice in Hospitality and Tourism Research, edited by Radzi, S. M., Sumarjan, N., Chik, C. T., Zahari, M. S., Mohi, Z., Bakhtiar, M. F., \& Annuar, F. I., 327-331, Penang: CRC Press, 2015.

The World Tourism Organization. UNWTO Tourism Highlights 2015 Edition. Madrid: UNWTO, 2015 
van der Vliet, Nynke, and Redeker, Gisela. "Explicit and Implicit Coherence Relations in Dutch Texts," In The Pragmatics of Discourse Coherence: Theories and Applications, edited by Gruber, Helmet, and Redeker Gisela, 23-50. Amsterdam: John Benjamins Publishing, 2014.

West, Matt. HTML5 Foundations. West Sussex: John Wiley \& Sons, 2013. 